\title{
KILLING PEOPLE INTENTIONALLY, BY CHANCE
}

\section{By KIm Davies}

IN his discussion 'Peacocke and Kraemer on Butler's Problem' (Analysis 40.3, June 1980), E. J. Lowe argues that the symmetry between the cases involved in Butler's problem is such as to render our intuitive ascriptions of intentionality paradoxical. On the basis of further investigation of the symmetry, I offer a justification of our intuitions and so a solution to the problem. Look at these two situations. One is an ordinary dice game, won on the throw of a six. The second is a version of Russian Roulette, called $R_{2}$, in which the player spins the barrel of a six-chambered gun containing one live cartridge, aims at the opponent, and pulls the trigger. If the bullet is fired, and hits the opponent, the game is won. We suppose that the death of the opponent is a causal consequence; to make the parallel exact, let us suppose that as a causal consequence of throwing a six in the dice game the Mona Lisa is presented to the thrower.

Now look at an asymmetry between throwing a six and killing Smith. If there is evidence that Brown intended to kill Smith anyway, not just in the game of $R_{2}$ but by any suitable method; and if the game of $R_{2}$ was just one suitable opportunity (perhaps because it helped to disguise his intentions), then we would call the killing intentional. However, we would have to say that it was not intentional that on this particular occasion Brown kill Smith. For, having pulled the trigger, he has no control over whether the bullet is fired, nor over killing Smith, and it is inappropriate to describe doing something as intentional in the absence of any control over whether it is done. Similarly, if Brown intends, one way or another, to get the Mona Lisa, and the dice game is just one opportunity, then we would say that he got it intentionally, but not that he threw a six intentionally.

The asymmetry between throwing a six and killing Smith hangs on the fact that killing Smith is a consequence of hitting Smith with the bullet; a consequence which, unlike throwing a six, is the object of a general intention. That is, the scope of this intention is not limited to a particular occasion. While we can say that, on this particular occasion (of an $R_{2}$ game), it was intentional that Smith be killed (thus distinguishing it from other possible occasions where Smith is killed unintentionally), we cannot say that it was intentional that, on this particular occasion (of an $R_{2} 2$ game), Smith be killed. Similarly, getting the Mona Lisa, a consequence of throwing a six, can be the object of a general intention without it being intentional that in this particular attempt it be obtained. Neither the firing of the bullet under the conditions of $\mathrm{RR}_{2}$ nor the throwing of the six are intentional, since, having decided to 
make the attempt, Brown has control over neither. This case seems to me to be the basis of our intuitions here, and to show why we would say that Smith's killing, and not the throwing of the six, was intentional. Several important points remain to be made.

First, if it is the general intention to kill Smith, not limited to the conditions of $\mathrm{RR}_{2}$, which allows us to call the killing intentional, could we not have a matching intention to throw a six, not limited to the conditions of dice games? The answer is yes. That is, if we were prepared to replace the ordinary die with a cube having a six on each face, and if throwing a six with such a die would satisfy our intention, then we could say that, in the ordinary dice game, Brown intentionally threw a six (i.e., it was an object of a general intention), though it was not intentional that on this occasion he throw a six. The reason that calling the throw of a six intentional is so counter-intuitive, is that in talking of wanting to throw a six we presuppose that the normal conditions of die-throwing will obtain, i.e., that it is on any particular occasion beyond the control of the thrower and that if it were not beyond the player's control the six would not count. When talking of wanting to kill someone, we do not presuppose that the conditions of $R_{2}$ will obtain, i.e., that on any particular occasion it is beyond the control of the thrower. For we count someone as having killed someone else, whether it was in a game of $\mathrm{RR}_{2}$ or not.

Second: does the killing of Smith have to be the object of a general intention, which would consider and accept suitable alternative means to its end, in order to be intentional? Could Brown not set up the $\mathrm{R}_{2}$ situation with an intention to kill Smith in this particular game of $R_{2}$, and with no interest in Smith's death by other means or at other times? I think that, while Brown would rightly be held responsible for Smith's death, the answer to the second question must be no. Brown may want to kill Smith under these conditions, but a want, without control over the desired outcome, cannot itself constitute an intention. All we can properly ascribe to him is the intention to have a shot at it, so to speak. Given this intention, the ascription of intentionality to the actual killing implies a control over the killing which, having pulled the trigger, Brown does not have. However, since this is such a special occurrence, the fact that we should not call the killing intentional need not be thought counter-intuitive. Indeed our intuition might be that, if Brown genuinely intended to kill Smith he would have shot him there and then, without any of this barrel-spinning business.

Third: in the standard case described above, while the killing of Smith was intentional, it seems that hitting him with the bullet (the equivalent of throwing a six on the left-hand side of the table) was not intentional-even though hitting Smith with the bullet is surely what we mean by shooting Smith, and out intuition is to say that the shooting, 
as well as the killing, of Smith was intentional. Meanwhile our intuition about the parallel act of throwing a six is that it was not intentional. Does the paradox lie here? The problem here can be solved by again looking at the normal conditions of throwing a six-where a one-in-six chance is central-and of shooting people. Someone counts as shot whether it was a one-in-six chance or not. Normally it is not, normally it is within the agent's control, and so normally it is intentional that, on the particular occasion, someone be shot. To make the parallel with throwing a six exact, we should describe the case as one of 'shooting Smith under the conditions of RR2', or 'hitting Smith with the bullet in a game of RRz', and not as 'shooting Smith' simpliciter. It does not seem counterintuitive to say that the shooting of Smith under the conditions of $R_{2}$ is not intentional, for, having entered the game, Brown has no control over its result.

Fourth: what part does hope play in all this? For Brown's hoping to kill Smith as he pulls the trigger seems an important factor in our intuitive ascription of intentionality to the killing. While some people may kill themselves intentionally by playing Russian Roulette, others may have no desire whatever to die, and we do not intuitively say that they kill themselves intentionally. It is just bad luck. The same goes, mutatis mutandis, for Brown and Smith. The hope figures as evidence of Brown's general intention to kill Smith. There may be cases where it is insufficient evidence. If $R_{2}$ is set up as a test of nerve and Brown, to his surprise, finds himself hoping that he does kill Smith as he pulls the trigger, and if he then fails, and heaves a sigh of relief, we do not normally count this momentary hope as evidence of intention. If, on the other hand, it is followed by future attempts on Smith's life, we might then cite this hope as the emergence of an intention to kill Smith. Of course, if Brown succeeds, we have no way of deciding this issue, which may be the cause of some guilt feelings on Brown's part. We would have to settle counterfactual questions such as whether, if Brown had lost all interest in the game for its own sake, he would still have pulled the trigger, or whether, if he had failed, he would have sought other opportunities to kill Smith. What is at stake here is determining whether Brown did act under a general intention to kill Smith, and the mere presence of hope, of the wish that he kill Smith, is not usually sufficient. Where the intention is there, we have the standard situation discussed earlier.

Finally, consider Lowe's most striking presentation of the paradox, in which Brown throws a die constructed as a bomb which will explode if and only if it turns up six, and in which Brown throws the die hoping that it explodes, and knowing that if and only if it explodes it will kill Smith. Lowe suspects that we would say that Brown exploded the bomb and killed Smith intentionally, but not that he threw a six inten- 
tionally. I suspect he is right, but disagree that it would be unjustified. For if Brown's hope that Smith die is evidence that Brown is acting under a general intention to kill Smith, then he kills Smith intentionally. Further, either exploding the bomb should be redescribed as 'exploding the bomb under conditions like those of $\mathrm{RR}_{2}$ ', in which case it is not intentional; or we should take Brown as intending generally to explode a bomb killing Smith, though not necessarily under these conditions, in which case Brown explodes the bomb intentionally, though it is not intentional that at this particular attempt he explode the bomb, since having embarked on the attempt he has no control over its outcome. Throwing a six is not intentional, for familiar reasons. What we cannot allow, although the focus on the particular situation seems to lead us to it, is to say that it is intentional that on this particular occasion, under the conditions of $\mathrm{RR}_{2}$, Brown kill Smith; for having embarked on the attempt Brown has no control over whether he throws a six, explodes the bomb, or kills Smith. Our intuitive ascriptions of intentionality sensibly take into consideration intentions which are not limited to particular occurrences in this way.

\section{KILLING, LETTING DIE, AND EUTHANASIA: A REPLY TO HOLLY SMITH GOLDMAN}

\section{By Philippa Foot}

G OLDMAN tries to show that 'so far as the intrinsic nature of the act goes, we cannot accept passive euthanasia without accepting active euthanasia as well' (ANALYSIS 40.4, October 1980, p. 224). Her argument runs as follows.

If it is true that, other things being equal, it is worse to kill someone than to allow him to die, and worse to set his house on fire than to fail to extinguish a fire that is burning, it is true only because these are applications of the general principle that, other things being equal, it is worse to barm a person than merely to allow this barm to come upon bim. She concludes that as an act of euthanasia is acceptable only when death counts as a good to the person who dies, the principle does not apply, and therefore the distinction between active and passive cannot affect the acceptability of acts of euthanasia.

I do not know why Goldman thinks that if it is worse to kill someone than to allow him to die this can only be on account of the principle she quotes. It is true that there is this principle, applicable only to 